\title{
Interstitial high-dose rate brachytherapy as boost for anal canal cancer
}

\author{
Alexander Tuan Falk ${ }^{1,2}$, Audrey Claren ${ }^{1,2}$, Karen Benezery ${ }^{1}$, Eric François ${ }^{3}$, Mathieu Gautier ${ }^{1}$, Jean-Pierre Gerard ${ }^{1}$ \\ and Jean-Michel Hannoun-Levi ${ }^{1,2^{*}}$
}

\begin{abstract}
Aim: To assess clinical outcomes of patients treated with a high-dose rate brachytherapy boost for anal canal cancer (ACC).

Methods: From August 2005 to February 2013, 28 patients presenting an ACC treated by split-course external beam radiotherapy (EBRT) and HDR brachytherapy with or without chemotherapy in a French regional cancer center in Nice were retrospectively analyzed.

Results: Median age was 60.6 years [34 - 83], 25 patients presented a squamous cell carcinoma and 3 an adenocarcinoma; 21 received chemotherapy. Median dose of EBRT was 45 Gy [43.2 - 52]. Median dose of HDR brachytherapy was 12 Gy [10 - 15] with a median duration of 2 days. Median overall treatment time was 63 days and median delay between EBRT and brachytherapy was 20 days. Two-year local relapse free, metastatic free, disease free and overall survivals were $83 \%, 81.9 \%, 71.8 \%$ and $87.7 \%$ respectively. Acute toxicities were frequent but not severe with mostly grade 1 toxicities: $37 \%$ of genito-urinary, $40.7 \%$ of gastro-intestinal and $3.7 \%$ of cutaneous toxicities. Late toxicities were mainly G1 (43.1\%) and G2 (22\%). Two-year colostomy-free survival was $75.1 \%$, one patient had a definitive sphincter amputation.
\end{abstract}

Conclusion: High-dose rate brachytherapy for anal canal carcinoma as boost represents a feasible technique compared to low or pulsed-dose rate brachytherapy. This technique remains an excellent approach to precisely boost the tumor in reducing the overall treatment time.

Keywords: Brachytherapy, Anal canal cancer, High-dose rate, Boost, Radiotherapy

\section{Introduction}

Anal canal carcinoma (ACC) is a rare disease with an incidence rate of less than 10 cases per 1000000 habitants in Europe [1], which has been considered as a life deteriorating even when cured because of sphincter amputation caused by historical surgical treatment. The impact on quality of life has pushed clinicians to consider new treatment ways. Conservative treatments for sphincter preservation in ACC have become a standard, even for large tumors. Gold standard treatment consists of concomitant radiotherapy and chemotherapy with Mitomycin and 5-Fluorouracil [2-4]. Clinical target volume consists of the gross tumor volume and the loco-regional lymph

\footnotetext{
* Correspondence: jean-michel.hannoun-levi@nice.unicancer.fr

'Department of Radiation Therapy, Antoine Lacassagne Cancer Center, 33, Avenue de Valombrose, 06189 Nice, Cedex, France

2University of Nice Sophia-Antipolis, Nice, France

Full list of author information is available at the end of the article
}

nodes with a dose of 45 to 50 Gy with a sequential boost delivered by either external beam radiation therapy (EBRT) or by interstitial brachytherapy (BCT) [5,6]. All attempts to find a better standard of chemotherapy have failed [7]. However, recent development of radiotherapy technique have permitted better care and new treatment strategies for ACC $[8,7]$.

There is no agreement for the boost technique. Standard brachytherapy technique remains based on LDR or PDR $[9,10]$. However as proposed for numerous tumors (prostate [11] and cervical cancer [12]) HDR brachytherapy appears to be more and more used mainly because of radioprotection considerations, dose distribution optimization and shorter treatment time [13]. Currently, there is few available data focusing on high-dose rate brachytherapy for ACC. This study was aimed to assess clinical outcomes of 
patients treated with a HDR brachytherapy boost for anal canal cancer.

\section{Material and methods Patient features}

This study retrospectively analyzed the clinical outcome of patients with histology-proven ACC treated by splitcourse radiotherapy and HDR brachytherapy with or without chemotherapy in the Centre Antoine Lacassagne, a regional cancer center in Nice, France. The study design and analysis was approved by the local institutional ethic comity of Antoine Lacassagne Cancer Center.

From August 2005 to February 2013, 28 patients were retrospectively analyzed. All the patients had a clinical exam and follow-up done by trained physicians of the center. According to local rules, patients underwent a digital rectal examination with a dated schema, anuscopy, computed-tomography scan, magnetic resonance imaging and endorectal ultrasonography. PET-scan was performed at the discretion of the physician. Tumors were staged using the UICC-cTNM classification $\left(2002-6^{\text {th }}\right.$ edition). All the patients presenting with a tumor involving no more than $2 / 3$ of the anal canal circumference were eligible for brachytherapy boost. Due to a high risk of necrosis/stenosis, circumferential tumor was considered as a definitive exclusion criteria for brachytherapy.

\section{Treatment features}

\section{Concomitant radio-chemotherapy}

The first part of the treatment consisted of EBRT with or without concurrent chemotherapy. Radiotherapy delivered a total dose of 45 to 46 Gy in 25 or 23 fractions based on a 3-dimensional conformational technique with or without intensity modulated. The dose was delivered to the ICRU point (International Commission on Radiation Units Measurements) using high-energy X-photons (>10 $\mathrm{MV})$. The clinical target volume (CTV) was the whole pelvis. The planning target volume (PTV) was defined as a $1 \mathrm{~cm}$ margin around the CTV in all directions. Inclusion of the inguinal nodes was set at the discretion of the radiation oncologist.

Patients who received concomitant chemotherapy were administrated Mitomycin C - 5FU or Cisplatin - 5FU.

\section{HDR brachytherapy boost}

Brachytherapy boost was performed unless patients could not undergo general anesthesia or presented with a tumor invasion $>2 / 3$ of the circumference. HDR brachytherapy was performed after the patient recovered from perineal dermatitis. After a 2 day fiber free diet and enema the day before and one-hour before procedure. A digital exam and anuscopy were performed under general anesthesia in order to evaluate the tumor response after radio-chemotherapy.

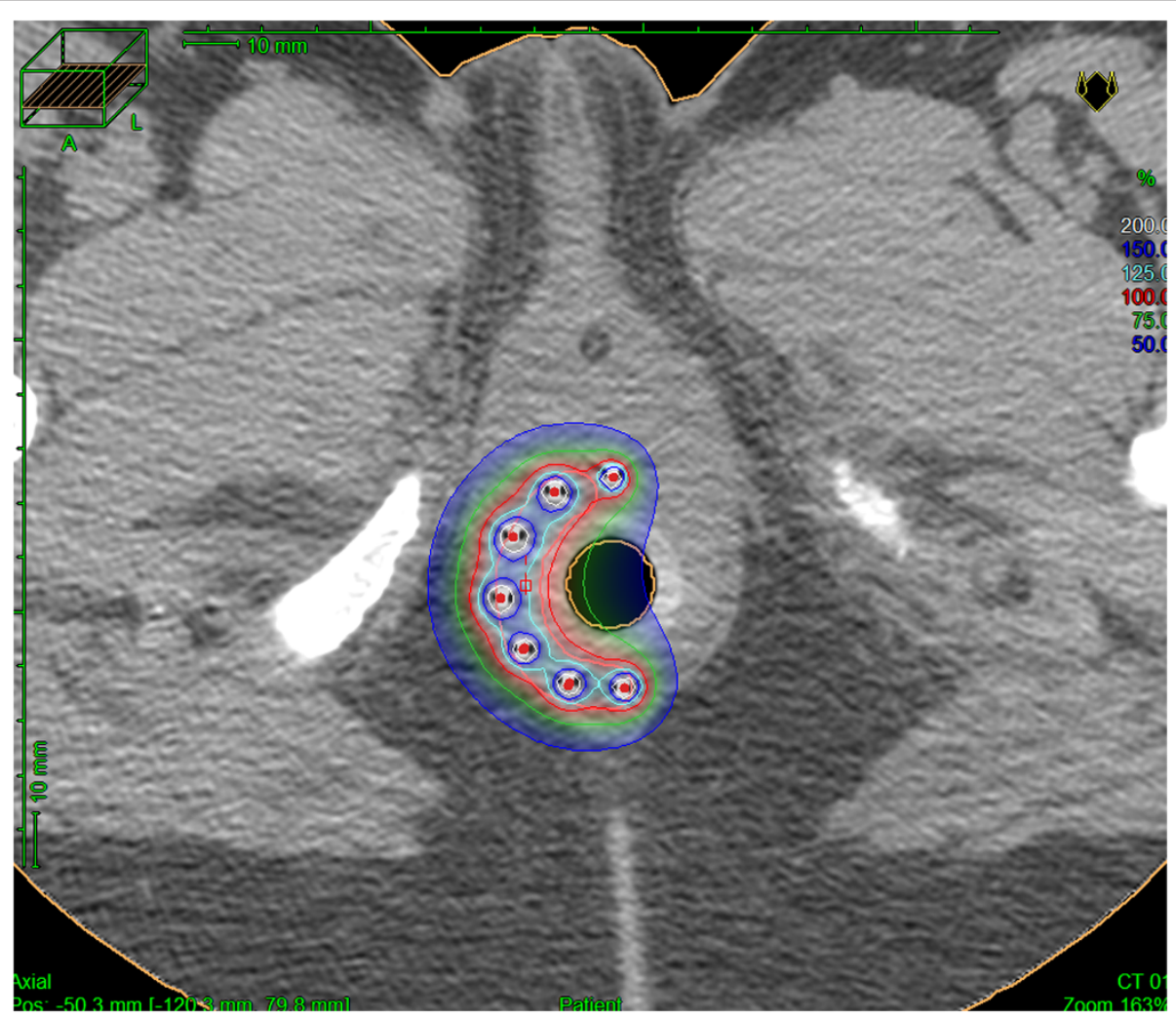

Figure 1 Dose distribution analysis on the post-implant CT-scan. 
A Foley catheter was first introduced into the bladder, then, needles (Sharp Needles ${ }^{\mathrm{Tw}}$; Nucletron, an Elekta company, Elekta AB, Stockholm, Sweden) were implanted under general anesthesia according to the pre-treatment target volume (based on the initial schema) respecting a minimal distance of 4 to $5 \mathrm{~mm}$ from the needles to the anal canal mucosa. We used a dedicated circular perineal template punched by a total of 10 holes (every $12 \mathrm{~mm}$ ) allowing to keep the implanted needles equidistant and parallel. A plastic tube $(20 \mathrm{~mm}$ in external diameter) was placed into the anal canal and fixed to the perineal template which was finally sutured to the skin. After recovery, post-implant planning CTscan was performed in the radiation oncology department for treatment planning purposes. CTV was delineated (anal canal initial tumor) using a $10 \mathrm{~mm}$ in diameter pearl.

Regarding the prescribed dose, our standard protocol was based on the result of the digital rectal exam performed under general anesthesia before the implant. In case of complete clinical response, a total dose of $12 \mathrm{~Gy}$ in 3 fractions over 24 hours $\left(\mathrm{EQD} 2_{\alpha \beta 3}=17 \mathrm{~Gy} / \mathrm{EQD} 2_{\alpha \beta 10}=\right.$ 15 Gy) was prescribed (1 fraction delivered the day of implant and 2 fractions at least 6 hours apart the day after). In case of partial clinical response, a total dose of $15 \mathrm{~Gy}$ in 3 fractions over 24 hours $\left(\mathrm{EQD} 2_{\alpha \beta 3}=24 \mathrm{~Gy} /\right.$ $\mathrm{EQD} 2_{\alpha \beta 10}=19 \mathrm{~Gy}$ ) was prescribed. Dose-volume adaptation was manually achieved using graphical optimization (OncentraBrachy, Nucletron, an Elekta company, Elekta $\mathrm{AB}$, Stockholm, Sweden) by dwell location and time variation (Figure 1). During the treatment, the patient was treated in his bed and hospitalized in a non-shielded room. After the last irradiation session, the needles were removed and the patient left the hospital the day after.

Regarding dosimetric results, D90 (dose delivered to $90 \%$ of the CTV) and D100 were reported as well as V100 (volume receiving $100 \%$ of the prescribed dose), V150 and V200. DHI (Dose Homogeneity Index: [V100-V150]/ V100) was also calculated.

\section{Follow-up and evaluation}

Patients were followed-up one month after HDR brachytherapy then, every semester with radiation oncologist and gastro-enterologist alternatively by clinical examination, endorectal ultrasonography and MRI if necessary. Local (LRFS) and metastatic (MRFS) relapse-free survivals as well as disease free (DFS), overall (OS) and colostomyfree (CFS) survivals were analyzed. Early and late toxicities rates were graded using the NCI-Common criteria version 4.0 [14].

\section{Statistical analysis}

All the data was analyzed using SPSS 20.0 (IBM Corporation). Overall survival was defined as the delay between date of diagnostic and the date of death. Relapse was defined as the delay between the date of diagnostic and the date of relapse. These statistics were estimated and represented graphically using Kaplan-Meier method. Patients were censored at the moment of their death or their last follow-up.

\section{Results}

Twenty-eight patients (pts) were analyzed in this study; patient characteristics are reported in Table 1. Median follow-up was 27.5 [4-98 months] and median age was 60.6 years [34-83 years]. Median initial tumor size was $3 \mathrm{~cm}[1-6 \mathrm{~cm}]$ and, using cTNM classification, the large majority of the patients were classified as T1/2 (90\%). Histologic subtypes were as follow: 25 pts presented a squamous cell carcinoma and 3 pts an adenocarcinoma. Two patients were HIV positive. Twenty-one patients (71.4\%)

\section{Table 1 Patient, tumor and treatment features}

\begin{tabular}{lll}
\hline Items & N/Median & Interval/\% \\
\hline Age (years) & 60 & {$[34-83]$} \\
Sex ratio (F/M) & 3 & \\
VIH Positive & 2 & 7.1
\end{tabular}

Tumor stage

$\begin{array}{lll}\text { T1 } & 5 & 17.9 \\ \text { T2 } & 20 & 71.4 \\ \text { T3 } & 2 & 7.1 \\ \text { T4 } & 1 & 3.6\end{array}$

Lymph node status

NO

N1

N2

$25 \quad 89.3$

2

7.1

gic type

SCC $\quad 25 \quad 89.3$

$\begin{array}{lll}A D C & 3 & 10.7\end{array}$

EBRT

\begin{tabular}{lll} 
Chemotherapy & 20 & 71.4 \\
Inguinal irradiation & 20 & 71.4 \\
Total dose (Gy) & 45 & {$[43.2-52]$} \\
HDR BT & & \\
$\quad$ d/f (Gy) & 4 & {$[3-5]$} \\
\# of fractions & 3 & {$[2-6]$} \\
Total dose (Gy) & 12 & {$[10-15]$} \\
\# of needles & 4 & {$[4-7]$} \\
TI EBRT/BT (days) & 20 & {$[4-63]$} \\
OTT (days) & 63 & {$[38-74]$} \\
\hline
\end{tabular}

SCC: squamous cell carcinoma; ADC: adenocarcinoma; EBRT: external beam radiation therapy; HDR BT: high-dose rate brachytherapy; d/f: dose per fraction; TI EBRT/BT: time interval between external beam radiation therapy and brachytherapy; OTT: overall treatment time. 
Table 2 Dosimetric data

\begin{tabular}{|c|c|c|}
\hline Data & Median & Interval \\
\hline $\mathrm{CTV}(\mathrm{cc})$ & 22.3 & {$[8.6-46.7]$} \\
\hline D90\% & 108 & {$[32-117]$} \\
\hline EQD2 aß10 (Gy) & 15.1 & {$[5.5-20.6]$} \\
\hline EQD2 aß3 (Gy) & 18.1 & {$[6.9-26.4]$} \\
\hline D100\% & 77 & {$[20-95]$} \\
\hline EQD2 aß10 (Gy) & 10.9 & {$[3.4-14.4]$} \\
\hline EQD2 aß3 (Gy) & 13.3 & {$[4.3-18.5]$} \\
\hline \multicolumn{3}{|l|}{ V100 } \\
\hline$\%$ & 96 & {$[58-100]$} \\
\hline $\mathrm{CC}$ & 18 & {$[8.1-45.8]$} \\
\hline \multicolumn{3}{|l|}{ V150 } \\
\hline$\%$ & 37 & {$[26-57]$} \\
\hline $\mathrm{CC}$ & 7.2 & {$[2.5-26.6]$} \\
\hline \multicolumn{3}{|l|}{ V200 } \\
\hline$\%$ & 19 & {$[10-26]$} \\
\hline $\mathrm{CC}$ & 3.4 & {$[1.2-11.7]$} \\
\hline $\mathrm{DHI}$ & 0.58 & [0.42 - 0.99] \\
\hline
\end{tabular}

CTV: Clinical target volume; D90: dose delivered to $90 \%$ of the CTV; EQD2 $\alpha \beta 10$ : equivalent dose at 2 Gy per fraction for $\alpha \beta 10$ (tumor); EQD2 $\alpha \beta 3$ : equivalent dose at 2 Gy per fraction for $a \beta 3$ (normal tissues); V100: volume which received $100 \%$ of the prescribed dose; V150: volume which received $150 \%$ of the prescribed dose; V200: volume which received $200 \%$ of the prescribed dose; $\mathrm{DHI}$ : dose homogeneity index.

received chemotherapy (17 pts: 5 FU/Mitomycin-C and 4 pts received 5FU/Cisplatin). Patients received a median dose of EBRT of 45 Gy [43.2-52 Gy] over a median EBRT treatment time of 37 days [32-52 days]. Median dose for HDR brachytherapy was 12 Gy [10-15 Gy]. Median duration of brachytherapy was 2 days [2,3]. Median overall treatment time was 63 days [38-74 days] and median delay between EBRT and HDR brachytherapy was 20 days [4-63 days]. Dosimetric data are reported in Table 2. Briefly, median CTV was 22.3 cc [8.6 - 46.7 cc], V100 was 96\% [58 - 100\%] and median DHI was 0.55 [42 - 99].

In terms of clinical outcomes, 2-years LRFS and MRFS rates were $83 \%$ [Standard Error (SE) 7.8\%] and 81.9\% [SE 9.5\%] respectively (Figure $2 \mathrm{~A}$ and $2 \mathrm{~B}$ ). Two-year DFS and OS rates were $71.8 \%$ [SE 10.7\%] and 87.7\% [SE 8.2\%] (Figure $3 \mathrm{~A}$ and $3 \mathrm{~B}$ ) respectively.

Acute toxicities following HDB ( $<2$ months) were frequent but not severe. Indeed, genito-urinary (GU), gastrointestinal (GI) and cutaneous toxicities were always grade 1 (G1) and occurred in 37\%, 40.7\% and 3.7\% respectively. Late toxicities were mainly G1 (43.1\%) and G2 (22\%). GI complications were: rectal bleeding (16.5\%), perineal pain (13.2\%), telangiectasia (13.2\%), diarrhea (9.9\%), rectal mucus $(9.9 \%)$, constipation (3.3\%), abdominal pain $(3.3 \%)$ and rectal pain (3.3\%). GU complications were: frequent urination (13.2\%), incontinence (6.6\%), hematuria (3.3\%), urgency (3.3\%). Two women (7.1\%) presented G3 late complications: the first (HIV-positive) with grade 2 rectal bleeding and grade 3 anal ulceration, with complete recovery after 5 years; the second with a grade 3 anal necrosis managed with colostomy. Two-year CFS was 75.1\% [SE 11.6\%] (Figure 4). Among the four patients (14.3\%) who underwent a colostomy, one was associated with a definitive sphincter amputation.

\section{Discussion}

Brachytherapy plays a key role in the management of ACC as boost after a first course of EBRT with or without concomitant chemotherapy [5]. From now, brachytherapy for ACC used mainly LDR or PDR. However, due to the

\section{A}

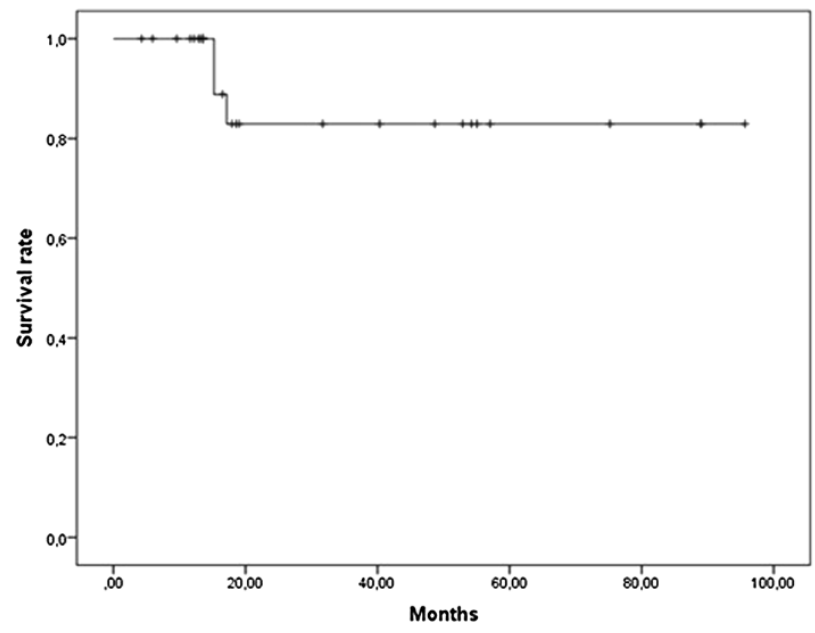

B

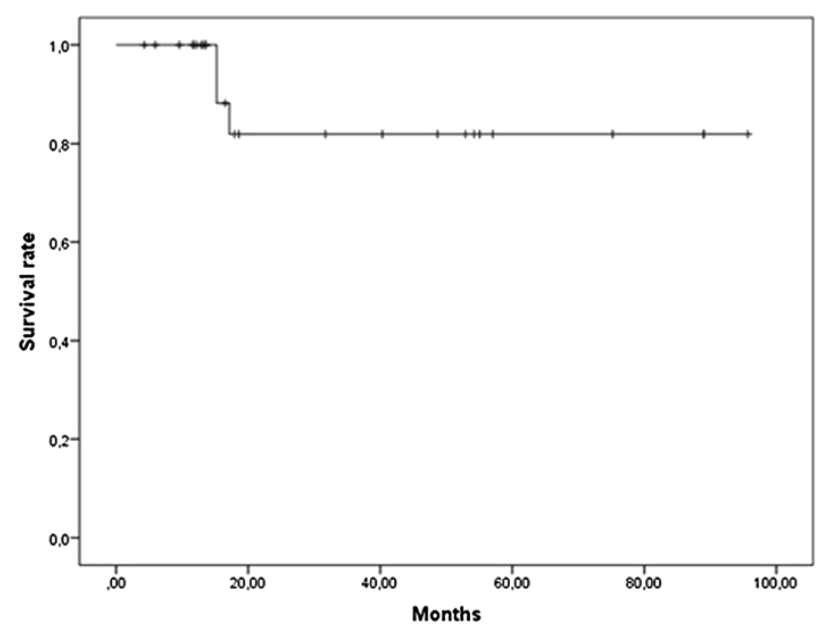

Figures 2 Kaplan-Meier curves for local disease free survival (A) and metastatic free survival (B). 

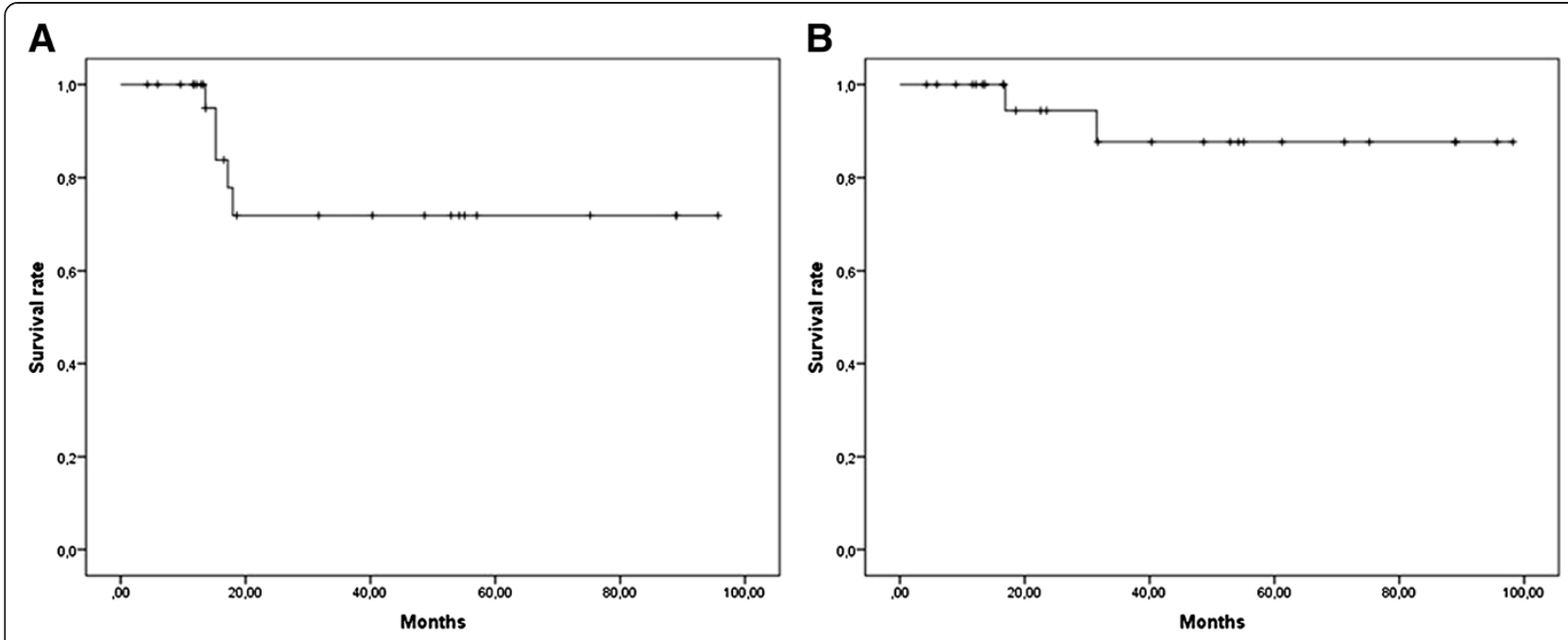

Figures 3 Kaplan-Meier curves for disease free survival (A) and overall survival (B).

possibilities of dose distribution optimization, but also radioprotection and cost-effective considerations, HDR brachytherapy gains, step by step, in respectability. While this technique represents a standard treatment for cervical [12] and prostate cancers [11], there is very few available data concerning ACC.

Optimization of dose distribution used with PDR/HDR brachytherapy represents in general a real advantage compare to LDR brachytherapy. However, specifically for ACC brachytherapy, because of the very proximal situation of the CTV in regards to the perineal template used (optimal needle guidance), the impact of dose optimization is maybe less important although adequate coverage of the anal mucosa (avoiding overdose area) appears more feasible. Classical dosimetric parameters used for HDR brachytherapy (CTV, D90, D10, V100, V150 and V200) can be used for ACC. Kapoor et al. [15] recently reported the results of 16 patients treated by radio-chemotherapy and HDR brachytherapy and presented dosimetric data with a mean DHI of 0.83 [0.55-0.98]. In our study, we reported a median DHI of 0.58 .

In terms of clinical outcomes, specifically regarding OS, CFS and toxicity $\geq \mathrm{G} 3$, it seems that our results are comparable to previous ACC brachytherapy series using LDR, PDR or HDR (Table 3). For LCR, our series reported a rate of $83 \%$ with a 27.5 median FU. This result

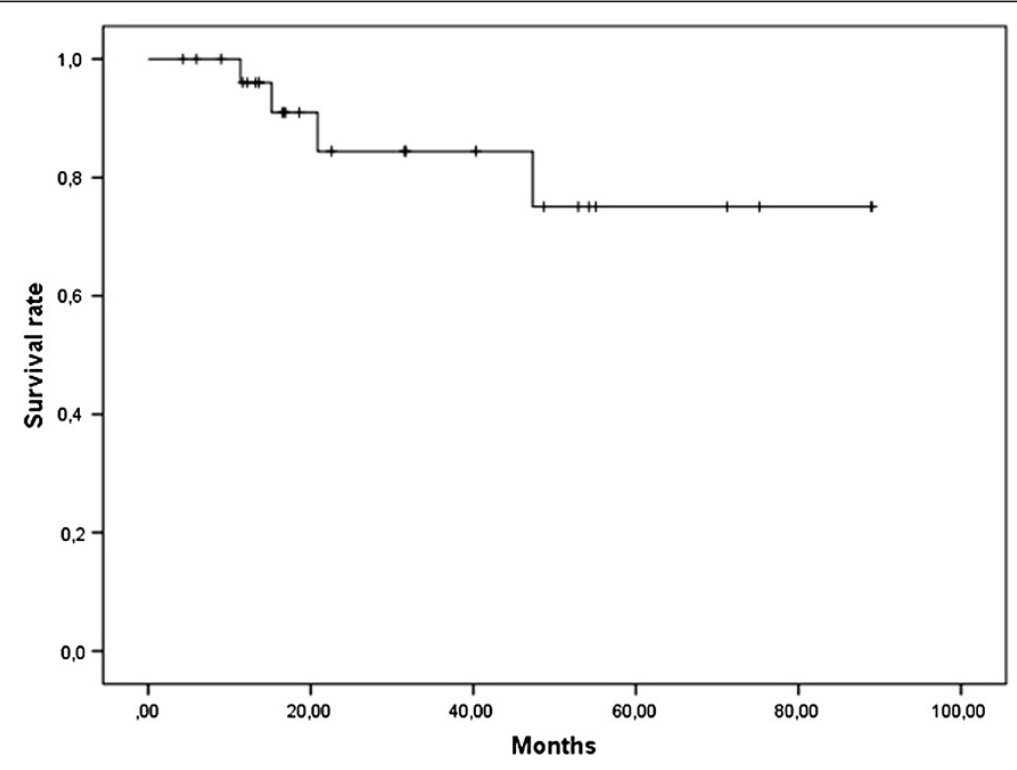

Figure 4 Colostomy-free survival. 
Table 3 Comparative overview of the literature focusing on brachytherapy boost for anal canal carcinoma according to the brachytherapy dose-rate

\begin{tabular}{|c|c|c|c|c|c|c|c|c|c|c|}
\hline \multirow[t]{2}{*}{ Authors (Year) } & \multirow[t]{2}{*}{$\#$ pts* } & \multirow[t]{2}{*}{ Median FU (months) } & \multirow[t]{2}{*}{ Dose Rate } & \multirow[t]{2}{*}{ Median BT dose (Gy) } & \multicolumn{2}{|l|}{ LR (\%) } & \multirow[t]{2}{*}{ OS (\%) } & \multicolumn{2}{|c|}{ Colostomy } & \multirow[t]{2}{*}{ Late toxicity $\geq \mathrm{G} 3[\%$} \\
\hline & & & & & LRR (\%) & $\overline{\text { LCR (\%) }}$ & & CR \% & CFS $\%$ & \\
\hline Peiffert et al. (1997) [16] & $101 / 118$ & 72 & LDR & 21.5 & N/A & & $60(5 y)$ & 9 & - & 13.5 \\
\hline Papillon et al. (1989) [17] & 221 & $>36$ & LDR & 20 to 30 & N/A & & $69.2(3 y)$ & 2.7 & - & N/A \\
\hline Wagner et al. (1994) [18] & 96 & 35.5 to $51.7^{* *}$ & LDR & $20.2^{* *}$ & 16.6 & - & $64(5 y)$ & N/A & & 9.25 \\
\hline Gerard et al. (1999) [19] & 19 & N/A & PDR & 10 to 25 & 5,2 & - & $100(1 \mathrm{y})$ & 0 & - & 0 \\
\hline Bruna et al. (2006) [20] & 71 & 28.5 & PDR & $17.8^{* *}$ & N/A & $90(2 y)$ & - & $89(2 y)$ & N/A & \\
\hline Roed et al. (1996) [10] & 17 & 11.3 & PDR & 28.85 & 23.5 & - & N/A & 47 & - & N/A \\
\hline \multirow[t]{2}{*}{ Kapp et al. (2001) [21] } & 39 & 31 & HDR & 6 to $12^{* * *}$ & & $81(3 y)$ & 80 (3 y DSS) & - & $78(3 y)$ & 7.6 \\
\hline & & & & & & $76(5 y)$ & 76 (5 y DSS) & & $73(5 \mathrm{y})$ & \\
\hline Vordermark et al. (2001) [5] & 20 & $52.8^{* *}$ & HDR & 5 to 12 & 5 & - & $84(5 \mathrm{y})$ & - & $68.9(5 y)$ & N/A \\
\hline Doniec et al. (2006) [23] & 50 & 34 & HDR & 8 to 12 & N/A & & $74(5 \mathrm{y})$ & 4 & - & N/A \\
\hline Oehler-Jänne et al. (2007) [24] & 34 & $60^{* *}$ & HDR & 14 & $10.3(5 y)$ & - & $66(10 y)$ & 15 & - & N/A \\
\hline Saarilahti et al. (2008) [25] & $29 / 59$ & 51 & HDR & 12 & N/A & & N/A & N/A & & N/A \\
\hline \multirow[t]{2}{*}{ Kapoor et al. (2013) [15] } & 16 & 41 & HDR & $18(6 f)$ & - & $87.5(2 y)$ & N/A & N/A & & 0 \\
\hline & & & & $21(7 f)$ & & & & N/A & & \\
\hline Falk et al. (2014) & 28 & 27.5 & HDR & $12(3 f)$ & - & $83(2 y)$ & 87.7 & - & $75.1(2 y)$ & 7.1 \\
\hline
\end{tabular}

*If ratio, number of patients treated by brachytherapy boost/total number of patients treated.

${ }^{* *}$ Mean.

***6 Gy during the EBT period and 6 Gy after EBT in case of partial response.

\# pts: number of patients; FU: follow-up; BT: brachytherapy; LR: local recurrence; LRR: local recurrence rate; LCR: local control rate; OS: overall survival; CR: colostomy rate; CFS : colostomy free survival; LDR: low-dose rate brachytherapy; PDR: pulsed dose rate brachytherapy; HDR: High-dose rate brachytherapy; NA: non-applicable; DSS: disease specific survival. 
Table 4 Overview of the literature focusing on external radiotherapy for anal canal carcinoma

\begin{tabular}{|c|c|c|c|c|c|c|c|c|c|c|c|}
\hline \multirow[t]{2}{*}{ Authors (Year) } & \multirow[t]{2}{*}{ EBT type } & \multirow[t]{2}{*}{ \# pts } & \multirow[t]{2}{*}{$\begin{array}{l}\text { Median FU } \\
\text { (months) }\end{array}$} & \multicolumn{2}{|c|}{$\begin{array}{l}\text { Median EBRT } \\
\text { dose (Gy) } \\
\end{array}$} & \multicolumn{2}{|l|}{ LR } & \multirow[t]{2}{*}{ OS (\%) } & \multicolumn{2}{|c|}{ Colostomy } & \multirow{2}{*}{$\begin{array}{l}\text { Late } \\
\text { toxicity } \geq \\
\text { G3 [\%] }\end{array}$} \\
\hline & & & & Initial & Boost & LRR (\%) & LCR (\%) & & CR \% & CFS \% & \\
\hline Northover et al. (2010) [5] & 2DRT & 290 & 157 & 45 & N/A & $57.1(5 \mathrm{y})$ & $33.7(5 \mathrm{y})$ & $53(5 y)$ & & $36.8(5 y)$ & N/A \\
\hline Northover et al. (2010) [5] & $2 \mathrm{DRT}+\mathrm{CT}$ & 295 & 157 & 45 & N/A & $32.3(5 y)$ & $46.6(5 y)$ & $58.1(5 y)$ & & $46.9(5 y)$ & N/A \\
\hline Ajani et al. (2008) [23] & 2DRT MMC-arm & 324 & 30 & 45 & $10-14$ & $25(5 \mathrm{y})$ & & $84 \%(5 y)$ & $10 \%(5 y)$ & & $11 \%$ \\
\hline \multirow[t]{2}{*}{ Kachnic et al. (2013) [24] } & IMRT & 43 & 24 & $42^{*}$ & $50.4^{*}$ & & $95 \%(2 y)$ & $94 \%(2 y)$ & & $90 \%(2 \mathrm{y})$ & $7 \%$ \\
\hline & & & & $50.4^{* *}$ & $54^{* *}$ & & & & & & \\
\hline
\end{tabular}

*For T1-T2 : 42 Gy with 50.4 Gy integrated boost on the tumor volume.

**For T3-T4 : 50.4 Gy with 54 Gy integrated boost on the tumor volume.

EBT: external beam radiation therapy; \# pts: number of patients; FU: follow-up; LR: local recurrence; LRR: local recurrence rate; LCR: local control rate; OS: overal survival; CR: colostomy rate; CFS : colostomy free survival; NA: non-applicable; DSS: disease specific survival; 2DRT: 2 dimension radiation therapy; CT: chemotherapy; MMC: Mitomycin-C; IMRT: intensity modulated radiation therapy; N/A: not applicable.

is quite comparable to those presented by the other HDR studies [16-19,15]. We reported a 2-year OS rate of $87.7 \%$. A historical clinical study published by Papillon et al. [9] focusing on LDR brachytherapy showed a $69.2 \%$ OS rate at 3 years. More recent PDR studies from Gerard et al. [20] and Bruna et al. [21] found respectively an OS rate of $100 \%$ at 1 year and $90 \%$ at 2 years. Lòpez Guerrera et al. [22] presented a mixed study of LDR and PDR brachytherapy with a 2-year OS rate of $87 \%$. These results are similar to those observed with external radiotherapy (Table 4).

Our patients presented frequent grade 1-2 toxicities but grade 3 toxicities only occurred for $7.1 \%$ of patients. Severe toxicities ( $\geq$ G3) were reported in 0 to $13.5 \%$ of patients in LDR/PDR studies $[9,25,26,10,20,27]$ and in 0 to $7.6 \%$ in HDR studies $[28,29]$. Only 2 patients presented severe grade 3 toxicities, one of them with an HIV-positive status which could account for higher toxicities [30]. Compared to our results, Kapoor et al. [15] reported no grade 3 toxicities with a similar LCR. This observation could be explained by the difference in terms of DHI with a less homogeneous implant in our cohort. On another hands, the total number of HDR brachytherapy fractions ranged between 6 and 7 in the Kapoor et al. study while in our cohort, the patients were treated with only 3 fractions (potential reduction of the hospitalization time). Nevertheless, our CFS rate (75.1\%) remains comparable to other published data on LDR, PDR and HDR brachytherapy $[16,28]$.

Due to its design, we weren't able to access quality of life. To our knowledge, there is no comparative assessing quality of life for brachytherapy boost. External radio chemotherapy seems to be associated with good quality of life with $77 \%$ patients being satisfied of their body [31]. Recent international guidelines have encouraged the study and evaluation of sexual, urinary and sphincter dysfunction as the data are scarce [32].

This study presented limitations. Data collection was retrospective and monocentric. Median follow-up was short (27.5 months). We didn't directly compare our data to low or pulsed-dose rate brachytherapy or EBRT boost.

HDR brachytherapy has advantages compared to low or PDR brachytherapy. It permits less radiation exposure for the medical staff and could provide better dose-distribution compared to LDR brachytherapy. Patients can be hospitalized in a non-shielded room allowing visits of the family (forbidden in case of LDR or PDR brachytherapy) with a potential improvement of psychological experience. Furthermore, with only one after-loader HDR machine, is it possible to treat many patients per day while for LDR or PDR, the number of treated patients per day will be strongly correlated to the number of shielded-rooms (potential cost-effective impact). To our knowledge, there are no prospective studies evaluating HDR brachytherapy for anal canal cancer boost after sequential EBRT. Further data needs to be collected and maybe even compared to LDR/PDR brachytherapy.

\section{Conclusion}

High-dose rate for anal canal carcinoma as boost represents a feasible technique compared to low or pulsed-dose rate brachytherapy. This technique remains an excellent approach to precisely boost the tumor in reducing the overall treatment time while high-dose rate is more and more used in the frame of brachytherapy. Currently simultaneous-integrated boost (SIB) in case of intensitymodulated EBRT represents a challenging therapeutic option which could be compared to HDR brachytherapy for ACC boost.

\section{Consent}

Written informed consent was obtained from the patient for the publication of this report and any accompanying images.

\section{Competing interests}

The authors declare that they have no competing interests. 


\section{Authors' contributions}

AF analyzed the clinical data managed the statistical analysis and wrote the manuscript; $A C$ analyzed the clinical data; KB revised the "results" and "discussion" sections; EF revised the "discussion" section; MG analyzed and revised the dosimetric results; JPG revised the manuscript; JMHL conceived, planned the study and co-wrote the manuscript. All authors read and approved the final manuscript.

\section{Author details}

'Department of Radiation Therapy, Antoine Lacassagne Cancer Center, 33, Avenue de Valombrose, 06189 Nice, Cedex, France. ${ }^{2}$ University of Nice Sophia-Antipolis, Nice, France. ${ }^{3}$ Departement of Medical Oncology, Antoine Lacassagne Cancer Center, Nice, France.

Received: 15 February 2014 Accepted: 16 October 2014

Published online: 06 November 2014

\section{References}

1. Faivre J, Trama A, De Angelis R, Elferink M, Siesling S, Audisio R, Bosset JF, Cervantes A, Lepage C: Incidence, prevalence and survival of patients with rare epithelial digestive cancers diagnosed in Europe in 1995-2002. Eur J Cancer 2012, 48:1417-1424.

2. Bartelink H, Roelofsen F, Eschwege F, Rougier P, Bosset JF, Gonzalez DG, Peiffert D, van Glabbeke M, Pierart M: Concomitant radiotherapy and chemotherapy is superior to radiotherapy alone in the treatment of locally advanced anal cancer: results of a phase III randomized trial of the European Organization for Research and Treatment of Cancer Radiotherapy and Gastrointestinal Cooperative Groups. J Clin Oncol Off J Am Soc Clin Oncol 1997, 15:2040-2049.

3. UKCCCR Anal Cancer Trial Working Party: Epidermoid anal cancer: results from the UKCCCR randomised trial of radiotherapy alone versus radiotherapy, 5-fluorouracil, and mitomycin. UKCCCR Anal Cancer Trial Working Party. UK Co-ordinating Committee on Cancer Research. Lancet 1996, 348:1049-1054.

4. Epidermoid anal cancer: results from the UKCCCR randomised trial of radiotherapy alone versus radiotherapy, 5 -fluorouracil, and mitomycin. Lancet 1996, 348:1049-1054.

5. Northover J, Glynne-Jones R, Sebag-Montefiore D, James R, Meadows $H$, Wan S, Jitlal M, Ledermann J: Chemoradiation for the treatment of epidermoid anal cancer: 13-year follow-up of the first randomised UKCCCR Anal Cancer Trial (ACT I). Br J Cancer 2010, 102:1123-1128.

6. Myerson RJ, Garofalo MC, Naqa IE, Abrams RA, Apte A, Bosch WR, Das P, Gunderson LL, Hong TS, Kim JJJ, Willett CG, Kachnic LA: Elective clinical target volumes for conformal therapy in anorectal cancer: an RTOG consensus panel contouring atlas. Int I Radiat Oncol Biol Phys 2009, 74:824-830.

7. Peiffert $D$, Giovannini M, Ducreux M, Michel P, François E, Lemanski C, Mirabel X, Cvitkovic F, Luporsi E, Conroy T, Gérard J-P: High-dose radiation therapy and neoadjuvant plus concomitant chemotherapy with 5 -fluorouracil and cisplatin in patients with locally advanced squamous-cell anal canal cancer: Final results of a phase II study. Ann Oncol 2001, 12:397-404.

8. Kachnic LA, Winter K, Myerson RJ, Goodyear MD, Willins J, Esthappan J, Haddock MG, Rotman M, Parikh PJ, Safran H, Willett CG: RTOG 0529: a phase 2 evaluation of dose-painted intensity modulated radiation therapy in combination with 5 -fluorouracil and mitomycin- $C$ for the reduction of acute morbidity in carcinoma of the anal canal. Int J Radiat Oncol Biol Phys 2013, 86:27-33.

9. Papillon J, Montbarbong JF, Gerard JP, Chassard JL, Ardiet JM: Interstitial curietherapy in the conservative treatment of anal and rectal cancers. Int J Radiat Oncol 1989, 17:1161-1169.

10. Bruna A, Gastelblum P, Thomas L, Chapet O, Bollet MA, Ardiet J-M, Gérard J-P, Peiffert D: Treatment of squamous cell anal canal carcinoma (SCACC) with pulsed dose rate brachytherapy: A retrospective study. Radiother Oncol 2006, 79:75-79

11. Hoskin PJ, Colombo A, Henry A, Niehoff P, Paulsen Hellebust T, Siebert F-A, Kovacs G: GEC/ESTRO recommendations on high dose rate afterloading brachytherapy for localised prostate cancer: an update. Radiother Oncol J Eur Soc Ther Radiol Oncol 2013, 107:325-332.

12. Viswanathan AN, Thomadsen B, American Brachytherapy Society Cervical Cancer Recommendations Committee, American Brachytherapy Society:
American Brachytherapy Society consensus guidelines for locally advanced carcinoma of the cervix. Part l: general principles. Brachytherapy 2012, 11:33-46.

13. Kolotas C, Zamboglou N: Role of interstitial brachytherapy in the treatment of malignant disease. Onkologie 2001, 24:222-228.

14. NCl Term Browser. [http://nciterms.nci.nih.gov/ncitbrowser/pages/ vocabulary.jsf?dictionary=Common\%20Terminology\%20Criteria\%20for\% 20Adverse\%20Events]

15. Kapoor R, Khosla D, Shukla AK, Kumar R, Gupta R, Oinam AS, Sharma SC: Dosimetric and clinical outcome in image-based high-dose-rate interstitial brachytherapy for anal cancer. Brachytherapy 2013. nº 4 (July 2014): 388-93. doi:10.1016/j.brachy.2013.09.006

16. Vordermark D, Flentje M, Sailer M, Kölbl O: Intracavitary afterloading boost in anal canal carcinoma. Results, function and quality of life. Strahlenther Onkol Organ Dtsch Röntgenges A/ 2001, 177:252-258.

17. Doniec JM, Schniewind B, Kovács G, Kahlke V, Loehnert M, Kremer B: Multimodal therapy of anal cancer added by new endosonographicguided brachytherapy. Surg Endosc 2006, 20:673-678.

18. Oehler-Jänne C, Seifert B, Lütolf UM, Studer G, Glanzmann C, Ciernik IF: Clinical outcome after treatment with a brachytherapy boost versus external beam boost for anal carcinoma. Brachytherapy 2007, 6:218-226.

19. Saarilahti $K$, Arponen $P$, Vaalavirta $L$, Tenhunen M: The effect of intensitymodulated radiotherapy and high dose rate brachytherapy on acute and late radiotherapy-related adverse events following chemoradiotherapy of anal cancer. Radiother Oncol 2008, 87:383-390.

20. Gerard J-P, Mauro F, Thomas L, Castelain B, Mazeron J-J, Ardiet J-M, Peiffert D: Treatment of squamous cell anal canal carcinoma with pulsed dose rate brachytherapy. Feasibility study of a French cooperative group. Radiother Oncol 1999, 51:129-131.

21. López Guerra JL, Lozano AJ, Pera J, Gutiérrez C, Cambray M, Ferrer F, Guedea F: Twenty-year experience in the management of squamous cell anal canal carcinoma with interstitial brachytherapy. Clin Trans/ Oncol Off Publ Fed Span Oncol Soc Natl Cancer Inst Mex 2011, 13:472-479

22. Ajani, Jaffer A., Kathryn A. Winter, Leonard L. Gunderson, John Pedersen, Al B. Benson, Charles R. Thomas, Robert J. Mayer, Michael G. Haddock, Tyvin A. Rich, et Christopher Willett. « Fluorouracil, Mitomycin, and Radiotherapy vs Fluorouracil, Cisplatin, and Radiotherapy for Carcinoma of the Anal Canal: A Randomized Controlled Trial ». JAMA 299, n 16 (April 2008): 1914-21. doi:10.1001/jama.299.16.1914.

23. Kachnic LA, Tsai HK, Coen JJ, Blaszkowsky LS, Hartshorn K, Kwak EL, Willins JD, Ryan DP, Hong TS: Dose-painted intensity-modulated radiation therapy for anal cancer: a multi-institutional report of acute toxicity and response to therapy. Int J Radiat Oncol 2012, 82:153-158.

24. Peiffert D, Tournier-Rangeard L, Gérard J-P, Lemanski C, François E, Giovannini M, Cvitkovic F, Mirabel X, Bouché O, Luporsi E, Conroy T, Montoto-Grillot C, Mornex F, Lusinchi A, Hannoun-Lévi J-M, Seitz J-F, Adenis A, Hennequin C, Denis B, Ducreux M: Induction chemotherapy and dose intensification of the radiation boost in locally advanced anal canal carcinoma: final analysis of the randomized UNICANCER ACCORD 03 trial. J Clin Oncol 2012, 30:1941-1948.

25. Wagner J-P, Mahe MA, Romestaing P, Rocher FP, Berger C, Trillet-Lenoir V, Gerard J-P: Radiation therapy in the conservative treatment of carcinoma of the anal canal. Int J Radiat Oncol 1994, 29:17-23.

26. Roed H, Engelholm SA, Svendsen LB, Rosendal F, Olsen KJ: Pulsed dose rate (PDR) brachytherapy of anal carcinoma. Radiother Oncol 1996, 41:131-134.

27. Kapp KS, Geyer E, Gebhart FH, Oechs AC, Berger A, Hebenstreit J, Stoeger H: Experience with split-course external beam irradiation \pm chemotherapy and integrated Ir-192 high-dose-rate brachytherapy in the treatment of primary carcinomas of the anal canal. Int J Radiat Oncol 2001, 49:997-1005.

28. Kapp KS, Kapp DS, Stuecklschweiger G, Berger A, Geyer E: Insterstitial hyperthermia and high dose rate brachytherapy in the treatment of anal cancer: A phase I/II study. Int J Radiat Oncol 1994, 28:189-199.

29. Oehler-Jänne C, Huguet F, Provencher S, Seifert B, Negretti L, Riener M-O, Bonet M, Allal AS, Ciernik IF: HIV-specific differences in outcome of squamous cell carcinoma of the anal canal: a multicentric cohort study of HIV-positive patients receiving highly active antiretroviral therapy. J Clin Oncol Off J Am Soc Clin Oncol 2008, 26:2550-2557. 
30. Provencher S, Oehler C, Lavertu S, Jolicoeur M, Fortin B, Donath D: Quality of life and tumor control after short split-course chemoradiation for anal canal carcinoma. Radiat Oncol 2010, 5:41.

31. Glynne-Jones R, Nilsson PJ, Aschele C, Goh V, Peiffert D, Cervantes A, Arnold D: Anal cancer: ESMO-ESSO-ESTRO clinical practice guidelines for diagnosis, treatment and follow-up. Radiother Onco. 111, $n^{\circ} 3$ (June 2014): 330-39. doi:10.1016/j.radonc.2014.04.013.

doi:10.1186/s13014-014-0240-4

Cite this article as: Falk et al.: Interstitial high-dose rate brachytherapy as boost for anal canal cancer. Radiation Oncology 2014 9:240.

\section{Submit your next manuscript to BioMed Central and take full advantage of:}

- Convenient online submission

- Thorough peer review

- No space constraints or color figure charges

- Immediate publication on acceptance

- Inclusion in PubMed, CAS, Scopus and Google Scholar

- Research which is freely available for redistribution 